\title{
Research on Risk Re-allocation Principles about the Price Fluctuation Du Yalan
}

\author{
School of Management, Tianjin University of Technology, Tianjin 300384, China
}

KEYWORD: project delay; price fluctuation; risk re-allocating; defaulters not to benefit

\begin{abstract}
Risk of price fluctuation during the period delay should be shared with the principle of defaulters not to benefit to adjust in contract sum. First we should make Risk re-allocating about the Price Fluctuation during the Project Delay because the division of responsibility principle is not reasonable; secondly, we re-share the risk of price fluctuation during project delays from the principle of defaulters not to benefit and conclude that defaulters not benefitting is a fast path to solve the risk of price fluctuation during project delays and eventually achieve a reasonable risk sharing.
\end{abstract}

\section{INTRODUCTION}

In engineering practice, due to the phenomenon of a party's default or force majeure caused the delay of the project, the incomplete contract can not cover all the risks. When the risk of price fluctuation occurs during the period of the construction period, the risk sharing scheme is still the focus of the dispute be-tween the two parties.

In this paper, we discuss how to deal with the price fluctuation during the period of the construction pe-riod from the principle of responsibility imputation. Put forward once the delay occurred during the fluc-tuation of price risk, and the initial risk sharing schemes cannot apply new risk or to perform an ini-tial risk sharing scheme will obviously unfair, default does not benefit principle can be as risk sharing the basic principle to adjust the contract price. This study provides a quick way to solve these disputes, and provides an effective way to achieve reasonable risk sharing.

\section{THE DIVISION OF RESPONSIBILITY AND THE RISK RE ALLOCATION OF PROJECT DELAY}

\section{Division of liability for project delay}

Construction period delay is divided into s single-event delay and concurrent delay. Single-event delay refers to that within the same period, only one delay event occurs, which does not cross with other delay events, and the delay event can exert impact on one or more processes. In terms of the inexcusable project delay caused by the contractor, the responsible party is the contractor; with respect to the excusable and compensable project delay caused by the owner, the responsible party will be the owner, who shall compensate a reasonable construction period and cost to the contractor; regarding the excusable and non-compensable project delay caused by objective reasons, both sides shall jointly bear the responsibility, and the owner shall compensate a reasonable construction period to the contractor.

Concurrent delay refers to that two or more events occur within the same period, the responsible parties involve the owner, contractor, objective factors and other aspects, and different events influence and interact on each other. With regard to the division of liability for concurrent delay, there are mainly the principle of initial event, the principle of not conducive to the subcontractor and the principle of responsibility allocation. The principle of initial event violates the "logic responsibility" reflected in the fair principle, it has its logical rationality, but it does not take into consideration the importance of interference events and their possible interactions within the crossed period. Besides, it also violates the provisions of the Contract Law of People's Republic of China concerning "in case both parties breach the contract, they shall assume their corresponding liabilities respectively", and it breaks the fair principle as well. The principle of not conducive to the subcontractor is not only illogical, but violates the fair principle. The principle of responsibility allocation is a compromise 
approach, though it conforms to the fair principle, it is quite hard to confirm responsibility proportion, and the final result is often to punish the contractor severely.

\section{Risk re-allocating by the price fluctation during the project delay}

The division of project delay responsibility is beneficial to risk re-allocating. Due to the construction cost of the construction project is affected by the market price fluctuations greatly, how to share the risk of changing in labor, materials and machinery fee become the focus of both contract disputes. Althought some would consider the risk in the contract, but because of most of the initial share schemes not considering about who should bear the responsibility for project delays lead to some unreasonable risk sharing, such as the appointment of the contractor should be determined the vary of project fee caused by the price change of labor, material or device during the implementation of the contract by themselves and take the corresponding risk consideration account in tender offer so as to contract price remain unchanged once price fluctuations occur have been wrote in some of the construction contract bidding documents. As a result, the employer often offer certain risk factors to contractor who will bear it.But the bidding documents of construction contract have not some rule about the charge change in labor, material or machine aspect after the period of project delay what is caused by the change of land acquisition, supply, geological conditions what should not owe to the contractor . Some scholars think that many project delay not caused by contractor .During the fellow construction period, the risk of price rising about market labor, material, mechanical what is not caused by contractor should not be undertook by the contractor and shall provide reasonable compensation. Visible,the risk sharing about the price fluctuation during the period of project delay under controversy.

\section{THE RISK OF PRICE FLUCTUATIONS IN THE SCHEDULING DELAY PERIOD SHOULD BE RE-ALLOCATE}

\section{Scheduling delay or extension break the time boundary of the contract}

Time boundary of the contract refers to contract period, if the actual duration does not match the contract period, then it breaks the time boundary of the contract. Since the initial risk-sharing is based on contract period, the risk of price fluctuations during the delay period has not been taken into account, or in some contracts it is considered.,but the "price fluctuations never regulate "include the risk of price fluctuations during the delay period to avoid the risk of price fluctuations. Because we advocate reasonable risk-sharing, the agreement "unlimited risk" is obviously unreasonable, and the mandatory provisions 3.4.1 in the 2013 edition of "Code of Bills of Quantities and Valuation for Construction Works" (hereinafter referred to as Version 13 " Code of Bills of Quantities and Valuation ") clearly states: Construction contracting must be clearly the content and scope of price risk in the bidding documents and contract,and can not specify it in the similar statements such as unlimited risk or all the risk.

Due to the time boundaries of the contract is broken, the contract status changes (ie, the Performance status of contract), we need to re-allocate risk.

\section{Price fluctuation during the period of the construction period shall be adjusted by the contract price}

The production of the dispute caused by price fluctuation in construction period delay that need to have three factors (the following chart):(1)construction period delay; (2)The risk sharing of breaking the time boundary is not agreed or the agreement is not reasonable; (3price fluctuation. 


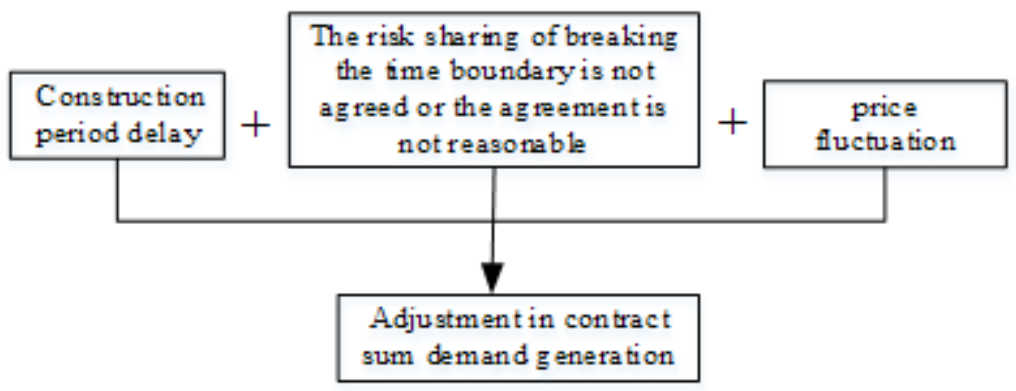

Figure 1 The three factors of adjustment in contract sum

These three factors are interrelated, influenced and interacted, which lead to the production of the dispute. The adjustment in contract sum is the main way to re-share the risk during the construction period. First, the project delay is a prerequisite; secondly, The risk of breaking the time boundary of the share is not agreed or agreed unreasonable that is contract price adjustment disputes hidden dangers; the contract price fluctuation is the trigger point of the price adjustment dispute. Such disputes arising from the contract, the contract price should be adjusted. The adjustment process of the contract price is the process of risk re - sharing.

\section{DEFAULTERS NOT BENEFIT PRINCIPLE IS THE REASONABLE PRINCIPLE}

The adjustment for contract price during project delay or time limit postpone belongs to the process to share the risk of incomplete contract. Causes of project delay or time limit postpone includes three types: Employer, contractor and the force majeure. Price may rise or fall during project delay or extension, and the Employer and contractor also harbor different wishes towards the adjustment of project prices, thus they will hold different opinions on the scheme of price adjustment, and here it is able to effectively solve such disputes by carrying on price adjustment with "the principle of the defaulters not to benefit ".

\section{Defaulters not to benefit principle}

Defaulters not to Benefit Principle originated from the Negative Prevention Principles proposed in the British "Hudson Architectural and engineering contract", saying that "during the execution of the contract, one party shall not make benefits due to their own mistakes." It reflects the reciprocity of rights and obligations. Yin Yillin defines the Defaulters not to Benefit Principle as the following: In the construction field, any party who complies to the contact will be protected according to relevant laws and regulations, but for the party who does not perform the contract must ensure that nothing benefits from the breach. In addition, he also pointed out that in China's current engineering practice, Defaulters Not to Benefit Principle is mainly applied to price changes during the adjustment period caused by the owners.

Laws and regulations all guarantee that neither party will make benefits due to its breach of contract, and they must make modifications to the risk sharing program of the original contract. The rights and obligations of the property owners and contractors must be equal. Defaulters not to principle will show a strong applicability when one of the events that either party is in charge leading to the implementation of some unconscionable risk allocation scheme according to the original contract.

\section{The idea of “defaulters not to benefit”in Contract law of the people's Republic of China}

"Contract law" article 63 Performance at Government Mandated Price Where a contract is to be implemented at a price mandated by the government or based on government issued pricing guidelines, if the government adjusts the price during the prescribed period of de-livery, the contract price shall be the price at the time of delivery. Where a party delays in delivering the subject matter, the original price applies if the price has increased, and the new price applies if the price has decreased. Where a party delays in taking deliv-ery or making payment, the new price applies if the price has increased, and the original price applies if the price has decreased. 
Article 284 Contractor's Remedies in Case of Project Interruption Due to Reasons Attributable to Developer If an ongoing project is stopped or delayed due to any reason attributable to the developer, the developer shall take the appropriate measures to make up or mitigate the loss, and shall indemnify the contractor for its loss and out-of-pocket expenses arising from resulting work stoppage, slowdown, reshipment, re-dispatch of mechanical equipment, and excess inventory of materials and assemblies, etc . According to this clause, the contractor was entitled to claim the increased costs due to the project period, such as for the project period shall be extended accordingly caused by artificial wage increase, material price increase, Construction machinery one-shift leasing fee increase.

Can be expected, when overdue delivery of the event of default occurs after encountering guidance prices, if in accordance with the new price execution, delivery party as the party in breach, get the new price of spread income from the late delivery of events, in order to avoid default from the default behavior of profit must be implemented in accordance with the original price. However, if the Contractor fails to deliver the subject matter that delays the responsibility is the employer, at this time, the contractor in accordance with the implementation of the "contract law" in Article 63 will obviously make the employer benefit from, at this time should be back to default events who is the responsible party. If the delay is the responsibility of the employer, then the contractor can claim according to the "contract law" article 283rd and the provisions of article two hundred and eighty-four, as shown in figure 2 .

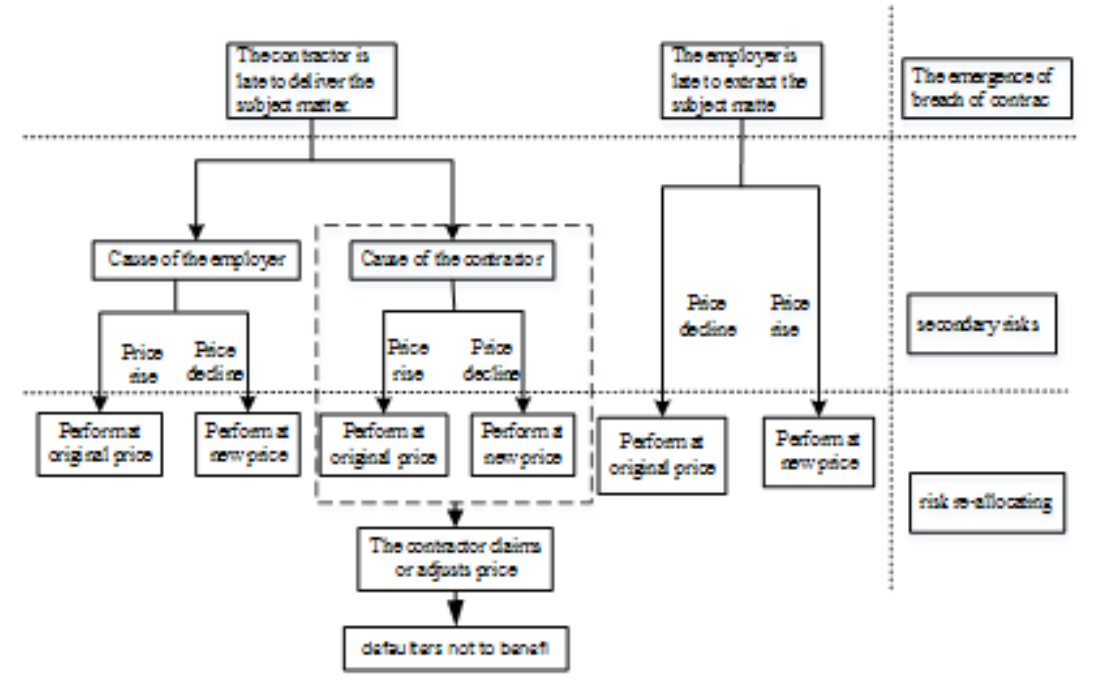

Figure 2 The idea of “defaulters not to benefit”in Contract law

In accordance with the above provisions, even contract both sides in the contract signed that the initial risk sharing contract price shall not be adjusted provisions, extended time limit for a project encountered during the period of rising prices, the contractor can also use default does not benefit principle to price adjustment or claim risk subdivision load, guarantee default not from its default behavior to benefit at the same time, prompting contract risk sharing tends to be rational.

\section{“Specifications of Charging on Bill of Quantities of Construction Projects Equations”(2013) directly to avoid the benefit of the breach of contract}

Code of bill of quantities and valuation for construction works (2013) 9.2 Changes in laws and regulations: 9.2.1 If the changes of national laws, rules, regulations and policies cause the project cost increasing or decreasing after the base date (28 days before tender closing date for Bidding project, or28 days before the signing of the contract for non-tender the project), contracting parties shall adjust the contract price in accordance with regulations accordingly issued by provincial or industry building department or authorized project cost management agency. 9.2.2 In case that schedule delays due to contractor, according to the adjustment time predetermined in 9.2.1, after the scheduled completion time of contract work, the contract price shall not be adjusted, if the amount increased; the contract price shall be adjusted, if the amount reduced. Thus, according to the idea of "those who do not benefit from the breach," adjusting the contract price is not conducive to the principle of 
defaulters to ensure that those who can not benefit from the breach, and protect the interests of the observant party will not be violated, as shown in figure 3 .

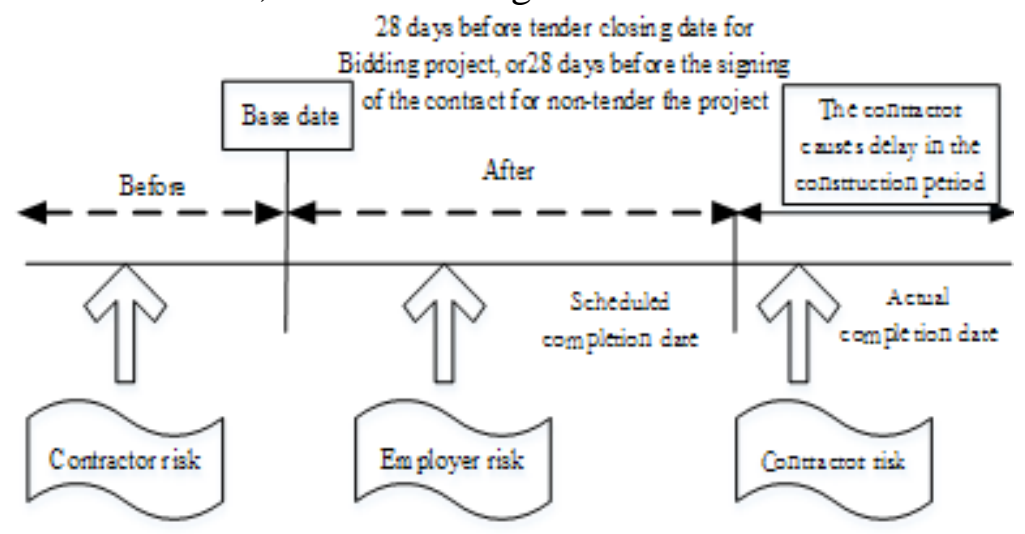

Figure 3. Change risk sharing of laws and regulations

So, due to reasons attributable to the contractor, the duration of the delay caused secondary risk, should follow the default does not benefit principle, namely due to one's own reasons caused by the event state occurrence changes cannot benefit from the change of state event, at your own risk.

\section{CONCLUSIONS AND IMPLICATIONS}

At this stage, Construction of long cycle and high supplies which decide the risk of price fluctuations will influence project construction and contract performance in large measure. But the risksharing scheme of price fluctuation that under the terms of contract signed and record node, is limited in the framework of time boundaries. When the occurrence of a certain event or multiple events leading to the implementation of the contract beyond the original framework, the original risk allocation scheme in response to the actual risk has manifestly unreasonable, and continues do it at the original share scheme may lead the responsible party gain extra benefits, which will undoubtedly contribute to social benefits that gain the benefit due to breach of contract, in violation of contract fairness, undermine social stability, and a departure from good custom justice.

Thus, given the high frequency of price fluctuation and the great surface of impacting, the principle of "defaulters do not benefit from breach " finds a quick fix path to solve price change during the duration of the adjustment period because of non-contractor's reason . By extension, the risks of break the contract's physical boundaries can also share risks each other according to the principle of " defaulters not to benefit ", such as the risk of engineering varietion , the risk of substandard quality. The principle of " defaulters not to benefit " need to be further research and application by scholars and practitioners.

\section{FUND PROJECT}

National Natural Science Foundation of China"Research on the Action Mechanism of Risk Allocation on Project Management Performance : Theory, demonstration and Application"

\section{REFERENCES}

[1]. Li Xuepeng. Research on the risk of engineering project management be based on Incomplete contract[J] Statistics and Decision,,2012,01:181-183.

[2]. Mao Mingzhu. Related Cost Recalculation due to Construction Period Delay not Resulting from Conductor. [J]. Heilongjiang Science and Technology of Water Conservancy,2011,03:147-148. 
[3]. Sun Na .Research on the Adjustment in Contract Sum Caused by the Price Fluctuation during the Project Delay:Based on the Code of Valuation with Bill of Quantity of Construction Works (2013) [J]. Value Engineering,2015,27:238-240.

[4]. Yang Degin .Study on the principle of delay claims with multi-event interference. [J] China Civil Engineering Journal, 2003,03:37-40+45

[5]. Yang Feixue \& Hong Chuanjun, Research on the claim events under the common delay the construction period [J]. Science Technology and Engineerin,2008,01:119-123.

[6]. Yin Yilin, 2013.Interpretation and interpretation of code of valuation with bill quantity of construction works. Bei Jing.China Building Industry Press, 